\title{
Article \\ Management of Aggression in Young Male Adults Using the Virtual Reality-Based Communication Modification Program
}

\author{
Junhyung Kim ${ }^{1,2}$, Young Hoon Jung ${ }^{1}$, Ki-Dong Baek ${ }^{1}$, Yeon-Ju Hong ${ }^{1}$, Hyu Seok Jeong ${ }^{1,3} \mathbb{D}$ \\ and Jae-Jin Kim ${ }^{1,3, *(1)}$
}

Citation: Kim, J.; Jung, Y.H.; Baek, K.-D.; Hong, Y.-J.; Jeong, H.S.; Kim, J.-J. Management of Aggression in Young Male Adults Using the Virtual Reality-Based Communication Modification Program. Appl. Sci. 2022, 12, 2424. https://doi.org/ 10.3390/app12052424

Academic Editor: Seongah Chin

Received: 24 December 2021

Accepted: 23 February 2022

Published: 25 February 2022

Publisher's Note: MDPI stays neutral with regard to jurisdictional claims in published maps and institutional affiliations.

Copyright: (C) 2022 by the authors. Licensee MDPI, Basel, Switzerland. This article is an open access article distributed under the terms and conditions of the Creative Commons Attribution (CC BY) license (https:// creativecommons.org/licenses/by/ $4.0 /)$.
1 Institute of Behavioral Science in Medicine, Yonsei University College of Medicine, Seoul 03722, Korea; jhcabilover@gmail.com (J.K.); yhoon_0802@hotmail.com (Y.H.J.); bgd432@naver.com (K.-D.B.); duswn317@hanmail.net (Y.-J.H.); hyosuc@yuhs.ac (H.S.J.)

2 Department of Psychiatry, Korea University Guro Hospital, Korea University College of Medicine, Seoul 08308, Korea

3 Department of Psychiatry, Yonsei University College of Medicine, Seoul 03722, Korea

* Correspondence: jaejkim@yonsei.ac.kr; Tel.: +82-2-2019-3341

Featured Application: Using the VR-based training program can be a starting point for developing more efficient methods for managing aggression in the general public.

\begin{abstract}
High aggression is common and costly for mental health problems in young adults. Because communication is a universal part of social relationships, including conflicts with others, it could be a possible target for mediating aggression. This study aimed to evaluate whether the virtual reality (VR)based communication modification program can be utilized for aggression management. Fifty-eight individuals with high aggression $(n=30)$ and with low aggression $(n=28)$ completed psychological assessments associated with aggression and functional communication, and they participated in the program, consisting of the three tasks: exploring the communication style, practicing functional communication, and expressing empathy. The participants' selections and their visual analog scale scores, in response to questions in the tasks, were collected as behavioral data. Results indicated that the high aggression group selected blaming dysfunctional communication style more frequently than the low aggression group. VR-based parameters, expected to reflect dysfunctional communicationrelated characteristics, showed significantly different correlations with aggression-related traits between the two groups. These findings show that our program may accurately represent an individual's aggressive traits and elicit the appropriate reaction.
\end{abstract}

Keywords: dysfunctional communication; aggression; virtual reality; communication modification

\section{Introduction}

High aggression is common and costly for mental health problems in people, especially adolescents and young adults [1,2]. Its negative effects on health and economics are felt throughout society [3-6]. Not only high aggression in criminal cases but also aggression that occurs in everyday relationships, such as gaslighting and dating violence, have been emphasized in social and economic costs [7,8]. Therefore, it is essential to develop effective interventions for managing aggression in daily life.

Although research over the past two decades has provided noteworthy progress in the development of interventions for managing aggression that demonstrate significant effects in terms of both efficacy and effectiveness [9-11], most studies in the field of interventions for aggression management have focused on aggressive behaviors that have already occurred, such as forensic events. It is problematic that the relevant service systems still struggle to meet the needs of people at risk of exhibiting such behavior [12]. Moreover, despite the diversity of situations in which everyday aggression can be revealed, most programs for managing aggression in daily life have focused on specific issues, such as 
dating violence, making it difficult to be provided generally [13,14]. Therefore, in order to manage the various aspects of day-to-day aggression, programs will need to have high accessibility, low-cost characteristics, and universal elements that can be used in common and various situations.

Communication is a universal element of all social relationships that people carry out, and it can thus become a common factor related to all day-to-day aggressions. Remarkably, several previous studies have reported that functional communication mediates stress by controlling conflict with others [15]. In contrast, nonfunctional communication interferes with everyday relationships, such as family health, and increases problem behaviors [16]. In this context, the modification of dysfunctional communication has already been emphasized in various social domains, including families [17], couples [18], healthcare workers [19], and schools [20]. Therefore, modifying dysfunctional communication can be an effective common target for managing a variety of daily life aggression. In addition, several psychological factors, such as anger and parent-adolescent communication, should be considered to modify dysfunctional communication [21,22].

Most representatively, the types of dysfunctional communication were proposed by Virginia Satir [23] and included placating, blaming, computing, and distracting [24,25]. Placaters are non-assertive and conflict-avoidant, tend to seek approval, and are sensitive to how others perceive them. Blamers are self-assertive without taking into account the position of others and always blame someone or something else. Computers favor an intelligent approach to analytically planning and solving problems and appear insensitive to the feelings of others. Distractors try to avoid issues or manipulate the emotions of others by using negative emotions to hide their feelings of inadequacy.

According to Satir's model, dysfunctional communication can be addressed by exploring the feelings, perceptions, and cognitive expectations of the self in here-and-now experiences [26,27]. This model has been applied to various populations, such as adolescents [28], college students [29,30], and couples [31], showing improvements in communication and interpersonal relationships. Concerning the application form, the model was also effective in various forms, such as learner-oriented education methods and role-playing forms [32,33]. Of note, here is a recent report that a counseling program based on Satir's model improved quality of life, including reducing aggression [34]. Based on these backgrounds, we developed a training program to modify dysfunctional communication, which used virtual reality (VR). It has been reported in our previous feasibility study that this program can be safely and effectively used for communication training [35].

VR has been widely studied as a tool with characteristics of high accessibility and low-cost in providing psychological interventions. With technological advancements, VR can easily provide realistic environments where individuals can communicate with others anytime, anywhere, and can increase the effectiveness of repetitive training by generating high immersion and strong motivation [36]. Considering these advantages, VR has been used to promote emotional/social adaptation skills in patients with mental illness, including autism spectrum disorder [37], schizophrenia [38], and social anxiety disorder [39]. VR has also well-established effectiveness in educational training for the general population, making it suitable as a tool to deliver practical and valid communication theory [40]. In addition, the advantages of VR include suitability for presenting emotional stimuli that can induce aggression [41]. Recent studies have actually reported that VR can be effectively used to manage aggressive behaviors in the context of emotional experiences [10,42-44]. Unlike these previous VR-based aggression management studies, our program attempts to modulate aggression using VR as a means of embodying the here-and-now experience of Satir's theory.

The purpose of this study was to investigate whether the participants' behaviors in the virtual environment related to dysfunctional communication reflect the characteristics related to aggression. Through this investigation, we tried to evaluate whether the VRbased communication modification program can be used for aggression management. The following research questions were addressed: (1) Will participants with high aggression 
demonstrate different patterns in the behavioral parameters of the program than those with low aggression? (2) Will the correlations between the behavioral parameters and psychological assessments scores for aggression and anger in participants with high aggression be significant and reflect the characteristics of high aggression?

\section{Materials and Methods}

\subsection{Participants}

A total of 217 young male adults were recruited through notices posted in seven Internet communities mainly used by college students to receive employment or academic information, and the recruitment was carried out for five months from May 2020. All of them provided the Aggression Questionnaire (AQ), Korean version (Cronbach $\alpha=0.86$ ) $[45,46]$, a 29-item five-point Likert scale, with higher scores indicating stronger aggressiveness, to be initially screened for defining cutoff values of two extreme groups in terms of aggression. Based on the distribution of the total AQ scores, 76 for the highest $25 \%$ group and 62 for the lowest $25 \%$ group were determined as the cutoff scores. A total of 60 volunteers (30 from the highest group and 30 from the lowest group) were selected as participants and were referred to as the high aggression (HA) and low aggression (LA) groups, respectively. Exclusion criteria were the current use of psychotropic medications and any history of a substance use disorder, neurological or neurodevelopmental disorder, major depressive episodes, bipolar I disorder, or psychotic disorders. The application of these criteria was made through the Mini-International Neuropsychiatric Interview [47] with a psychiatrist. Although all participants completed the program without giving up, two participants from the LA group were excluded from the analysis due to the unintended missing data from the VR-based interactive feedback program. The two groups (HA and LA) showed no significant difference in age $(23.3 \pm 2.5$ years and $23.6 \pm 2.7$ years, respectively) and education level (14.8 \pm 1.5 years versus $14.6 \pm 2.0$ years, respectively). All participants gave written informed consent after being informed about the procedure of the study. This study was approved by the Institutional Review Board of Yonsei University Gangnam Severance Hospital, South Korea.

\subsection{Psychological Assessments}

The results of the AQ were divided into four dimensions of aggression and summed up for analysis, which were physical aggression, verbal aggression, anger, and hostility [45]. In addition, two different self-report scales were used for evaluating the participants' psychological characteristics associated with aggression and communication. The StateTrait Anger Expression Inventory (STAXI), Korean version (Cronbach's $\alpha=0.72$ ) [48,49], a 44-item 4-point Likert scale, was used to assess state anger, trait anger, and anger expression. Of these, we included only three subscales for anger expression in the analysis, such as the eight-item anger expression-in scale measuring how frequently angry feelings are suppressed or inhibited, the eight-item anger expression-out scale measuring how frequently an individual expresses anger toward others or objects, and the eight-item anger control-out scale that measures the frequency with which an individual attempts to modify the anger experienced and to actively control the expression of anger. The Korean version (Cronbach's $\alpha=0.86$ ) of Parent Adolescence Communication Inventory (PACI), a 20-item five-point Likert scale, was used to assess the level of communication with parents on the open or closed dimension [50,51]. The higher open score corresponds to more freely expressing the thoughts and feelings without being oppressed, and the higher closed score represents less hesitance to express the opinions and more careful selection of dialogue material. Meanwhile, the Simulator Sickness Questionnaire (SSQ), a 16-item questionnaire [52], was used to investigate the occurrence and severity of cybersickness when immersed in virtual environments for program experience. 


\subsection{Task Procedure}

All participants experienced the VR-based interactive feedback program of about 45 min, 'Enhancing Functional Communication' once, that consisted of three tasks, such as exploring the communication style, practicing functional communication, and expressing empathy (Figure 1). The task procedures were identical in all respects to those detailed in the feasibility study of this program [35]. The VR system consisted of a desktop computer, an Oculus Rift head-mounted display with a tracker (Oculus VR LLC, Menlo Park, CA, USA), and the touch controller (Oculus VR LLC, Menlo Park, CA, USA). In all the tasks that were produced using a 3D video shot of the acting of professional actors, participants were advised to consider and talk in detail as they deemed appropriate in the given interpersonal situation. Participants performed all the tasks themselves while sitting on a comfortable sofa, and the researcher provided assistance only for the start and end of the tasks.
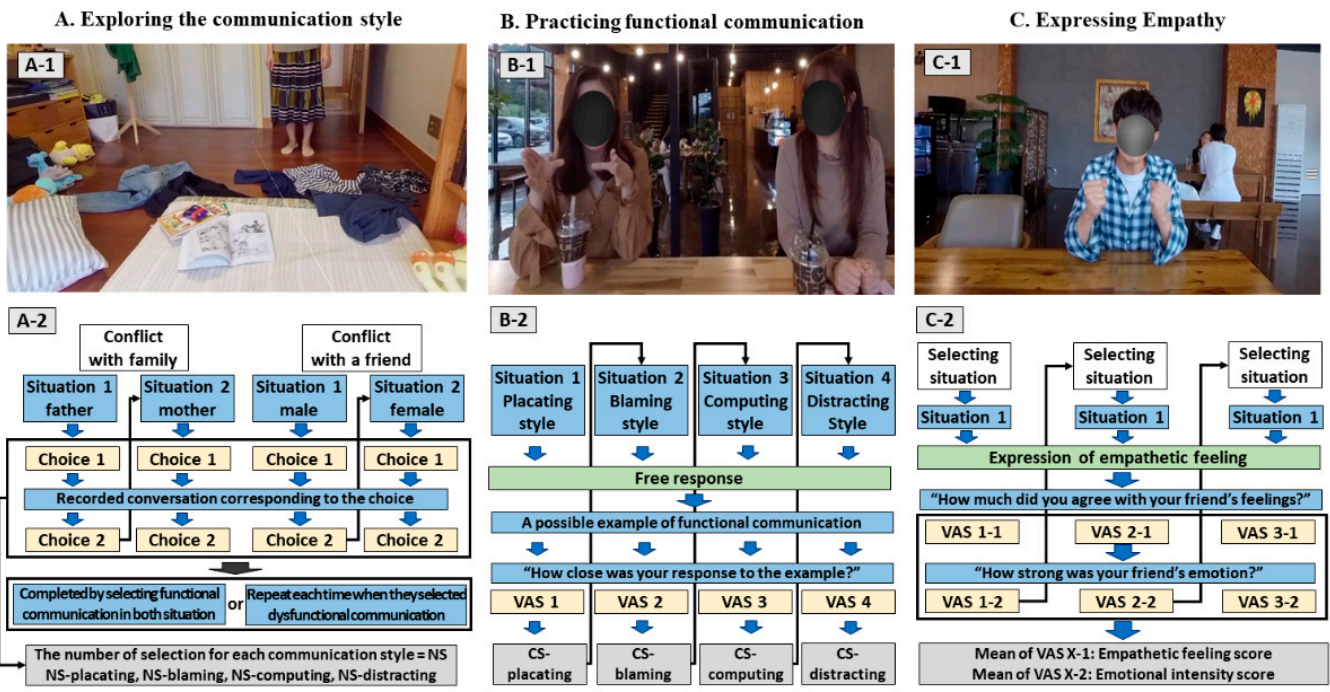

Figure 1. Screenshots and schematic diagrams of enhancing functional communication. Although the tasks were conducted in Korean, the procedure here is explained in English for the convenience of understanding. To protect the portrait rights of the cast, the faces are obscured. Abbreviation: VAS, visual analog scale; NS, the number of selections; CS, communication score.

In the task of exploring the communication style, participants experienced dysfunctional communication in two categories of interpersonal conflict situations: conflict with family and conflict with a friend (Figure 1A-1). Participants experienced two situations in each category in the order given: conflict with family: father and mother, conflict with a friend: male and female friends. Participants should select twice one of five response options reflecting the style of communication (placating, blaming, computing, distracting, and functional) in each situation. Specifically, after hearing emotional remarks from a virtual person, participants made the first choice (Choice 1) from five response options that most closely resembled the response they were most likely to actually make. Then, they experienced the recorded conversation consisting of their own reaction and the reaction from the virtual person corresponding to their selection. After experiencing the recorded conversation, participants had to choose the second selection (Choice 2). The next situation with another virtual person (mother or female friend) in the same category was presented and proceeded in the same way. Participants had to repeat the two situations each time they selected a dysfunctional communication style in any situation, and the task was completed by selecting the option of functional communication in both situations in each category. The number of selections for each dysfunctional communication style made before both categories were repeated was recorded and referred to as NS-placating, NS-blaming, NS-computing, and NS-distracting, respectively (Figure 1A-2). 
In the task of practicing functional communication, participants interacted with someone who communicated dysfunctionally in four different conflict-driven situations (Figure 1B-1). In each situation, participants listened to and freely responded to one of four dysfunctional communication styles (placating, blaming, computing, or distracting) exhibited by one of two or three others, and then listened to a possible example of functional communication via voice guidance. Next, they rated how close their response was to the presented example using a visual analog scale (VAS), which presented 'not at all' (0) at the left end and 'very much' (100) at the right end. The VAS score was referred to as the communication score with the placating, blaming, computing, or distracting style (abbreviation: CS-placating, CS-blaming, CS-computing, and CS-distracting, respectively) (Figure 1B-2).

In the task of expressing empathy, participants started with a virtual café with a friend and selected one of six options: nephew, near home, restaurant, movie, my room, and on the road. The friend told them about an event that evoked pleasure, fear, surprise, sadness, disgust, and anger, respectively (Figure 1C-1), depending on the selection, and they were asked to select and perform three situations among the options. For each selected situation, participants listened carefully to his/her story, understood his/her feelings, said what they wanted to tell him/her, and evaluated how much they agreed with his/her feelings and how strong his/her emotion was using the VAS scale. The VAS score from the initial trial of the three performed situations was used in the analysis, and the mean of the three VAS scores was referred to as the empathetic feeling score and emotional intensity score for the two respective questions (Figure $1 \mathrm{C}-2$ ).

\subsection{Statistical Analysis}

Descriptive statistics were provided to explore the demographic characteristics, psychological characteristics related to aggression, the sense of cybersickness, and the parameters obtained during each of the three tasks. Independent $t$-tests were conducted to compare the psychological assessments scores and behavioral parameters between the HA and LA groups. Significant Pearson correlation coefficients between the behavioral parameters and psychological assessments in the HA group were calculated. The z-tests after Fisher's transformation between the HA and LA groups were conducted to investigate whether the behavioral parameters reflect aggression-related characteristics differently. The threshold of statistical significance was an alpha level of 0.05. All analyses were performed using the Statistical Package for the Social Sciences 25.0 (SPSS Version 25.0; IBM Corporation, Armonk, NY, USA).

\section{Results}

\subsection{Psychological Assessments}

The HA and LA groups showed a significant difference in the total AQ scores $(77.7 \pm 15.4$ and $53.7 \pm 8.9$, respectively; $t 56=7.19, p<0.001)$. The other psychological scale scores are presented in Table 1. The HA group showed significantly higher scores in all AQ subscales than the LA group (all: $p<0.001$ ). The HA group also exhibited significantly higher scores in the anger expression-in $(p=0.001)$ and anger expression-out $(p<0.001)$ subscales of the STAXI and significantly lower scores in the anger control-out subscale $(p<0.001)$ than the LA group. However, the two groups showed no significant difference in the PACI and SSQ scores. 
Table 1. Mean and standard deviation (SD) of psychological scale scores in participants with high aggression and low aggression.

\begin{tabular}{|c|c|c|c|c|c|c|}
\hline \multirow[t]{2}{*}{ Variable } & \multicolumn{2}{|c|}{$\begin{array}{l}\text { High Aggression } \\
\quad(n=30)\end{array}$} & \multicolumn{2}{|c|}{$\begin{array}{l}\text { Low Aggression } \\
\qquad(n=28)\end{array}$} & \multirow[t]{2}{*}{$t$} & \multirow[t]{2}{*}{$p$-Value } \\
\hline & Mean & SD & Mean & SD & & \\
\hline $\mathrm{AQ}$ & & & & & & \\
\hline Physical aggression & 23.8 & 6.5 & 15.4 & 4.4 & 5.79 & $<0.001$ \\
\hline Verbal aggression & 16.5 & 4.6 & 12.0 & 2.7 & 4.47 & $<0.001$ \\
\hline Anger & 14.2 & 3.7 & 10.3 & 2.4 & 4.71 & $<0.001$ \\
\hline $\begin{array}{l}\text { Hostility } \\
\text { STAXI }\end{array}$ & 23.2 & 5.8 & 16.0 & 4.8 & 5.13 & $<0.001$ \\
\hline Anger expression-in & 19.2 & 4.3 & 15.3 & 4.4 & 3.46 & 0.001 \\
\hline Anger expression-out & 19.1 & 4.1 & 12.0 & 2.7 & 7.80 & $<0.001$ \\
\hline $\begin{array}{c}\text { Anger control-out } \\
\text { PACI }\end{array}$ & 19.2 & 4.6 & 24.0 & 3.7 & -4.34 & $<0.001$ \\
\hline Open communication & 68.3 & 17.4 & 74.9 & 15.5 & -1.50 & 0.138 \\
\hline Closed communication & 63.5 & 13.4 & 70.3 & 13.0 & -1.94 & 0.057 \\
\hline SSQ & 26.2 & 10.2 & 22.0 & 7.9 & 1.76 & 0.084 \\
\hline
\end{tabular}

AQ, Aggression Questionnaire; STAXI, State Trait Anger Expression Inventory; PACI, Parent Adolescence Communication Inventory; SSQ, Simulator Sickness Questionnaire.

\subsection{Behavioral Parameters}

The results of participants performing the three VR tasks are presented in Table 2. In the task of exploring the communication style, the NS-blaming was significantly greater in the HA group than in the LA group $(p<0.05)$, but the NS-placating, NS-computing, and NSdistracting showed no significant difference between the two groups (Figure 2). In the task of practicing functional communication, the communication scores were not significantly different in the interactions with all dysfunctional communication styles between the two groups. In the task of expressing empathy, the empathetic feeling score and emotional intensity score showed no significant difference between the two groups.

Table 2. Mean and standard deviation (SD) of the behavioral parameters in participants with high aggression and low aggression.

\begin{tabular}{|c|c|c|c|c|c|c|}
\hline \multirow[t]{2}{*}{ Variable } & \multicolumn{2}{|c|}{$\begin{array}{c}\text { High Aggression } \\
\quad(n=30)\end{array}$} & \multicolumn{2}{|c|}{$\begin{array}{c}\text { Low Aggression } \\
\quad(n=28)\end{array}$} & \multirow[t]{2}{*}{$t$} & \multirow[t]{2}{*}{$p$-Value } \\
\hline & Mean & SD & Mean & SD & & \\
\hline \multicolumn{7}{|c|}{ The task of exploring the communication style } \\
\hline NS-placating & 0.8 & 0.9 & 1.2 & 0.9 & -1.57 & 0.121 \\
\hline NS-blaming & 0.4 & 0.7 & 0.1 & 0.3 & 2.27 & 0.027 \\
\hline NS-computing & 1.1 & 0.9 & 0.7 & 1.0 & 1.58 & 0.120 \\
\hline NS-distracting & 1.2 & 1.3 & 1.4 & 1.1 & -0.51 & 0.609 \\
\hline \multicolumn{7}{|c|}{ The task of practicing functional communication } \\
\hline CS-placating & 67.2 & 19.3 & 67.8 & 17.9 & -0.12 & 0.905 \\
\hline CS-blaming & 62.4 & 22.0 & 58.1 & 24.8 & 0.69 & 0.492 \\
\hline CS-computing & 54.4 & 23.1 & 60.6 & 22.9 & -1.02 & 0.311 \\
\hline CS-distracting & 61.4 & 26.1 & 62.8 & 23.1 & -0.22 & 0.824 \\
\hline \multicolumn{7}{|c|}{ The task of expressing empathy } \\
\hline Empathetic feeling score & 34.8 & 7.7 & 36.0 & 6.5 & -0.65 & 0.522 \\
\hline Emotional intensity score & 40.3 & 5.9 & 42.8 & 5.0 & -1.69 & 0.097 \\
\hline
\end{tabular}

NS, number of selections; CS, communication score. 


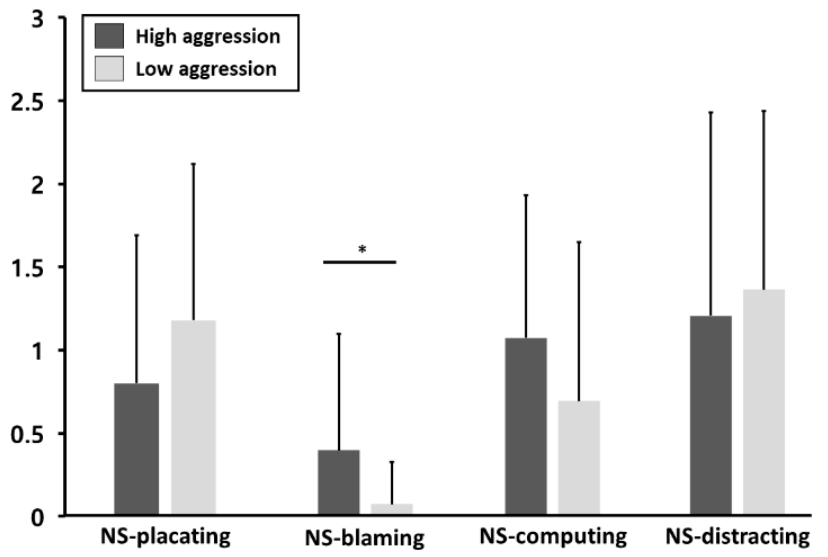

Figure 2. Comparison of the behavioral parameters obtained in the task of exploring the communication style between participants with high aggression and low aggression. Standard deviations are represented as error bars. ${ }^{*} p<0.05$.

\subsection{Relationship between the Behavioral Parameters and Psychological Assessments in the HA Group}

In the task of exploring the communication style, the NS-placating was negatively correlated with the anger control-out scores $(r=-0.422, p<0.05)$, and the NS-distracting was also negatively correlated with two dimensions of the AQ (physical aggression: $r=-0.41$, $p<0.05$; anger: $r=-0.40, p<0.05)$. The NS-blaming and NS-computing were not significantly correlated with any psychological scale scores. The behavioral parameters from the task of practicing functional communication showed no significant correlation with psychological assessments. In the task of expressing empathy, the empathetic feeling scores showed no significant correlation with any psychological scale scores, whereas the emotional intensity scores were positively correlated with the anger control-out scores $(r=0.54$, $p<0.01)$. Despite these significant correlations, the z-tests after Fisher's transformation showed that the significant difference between the HA and LA groups was found only in the correlation between the NS-distracting and AQ-anger $(Z=-2.01, p<0.05)$.

\section{Discussion}

The current study explored whether the behavioral parameters from the VR-based communication modification program effectively reflect participants' characteristics related to aggression. To compare the communication styles between individuals with marked differences in aggression levels, participants were recruited from the highest $25 \%$ and the lowest $25 \%$ groups of the AQ scores among young male adult volunteers. However, since they were all volunteers recruited from the general population, even the HA group had an average total $\mathrm{AQ}$ of $77.7 \pm 15.4$, not as high as $87.4 \pm 21.7$ for prisoners [53] and $97.2 \pm 21.2$ for dating violent offenders [54]. Nevertheless, our overall results suggest that individuals with high aggression display different ways of communicating compared to those with low aggression.

The significant difference in the task of exploring the communication style between the HA and LA groups was seen only in the NS-blaming. Since this task was configured in a format to select a communication type repeatedly, the number of selections may reflect an individual's preference for the communication style in interpersonal conflict situations. In the Satir model, communication was viewed as a coping method to survive while protecting oneself from anger experienced in an external conflict situation. It was explained that the experience of anger might be different between dysfunctional communication types. Specifically, placaters tend to be difficult to express anger, whereas blamers express anger indiscriminately [55]. Previous studies have demonstrated the higher the aggression, the more the anger is expressed to the outside through aggressive behaviors [56,57]. Therefore, 
greater NA-blaming in participants with high aggression seems to properly reflect their characteristics related to anger expression.

Additionally, the correlation analysis between the number of selections for dysfunctional communication type and psychological assessments showed different patterns between the two groups. Particularly, the NS-distracting showed a negative correlation with the AQ-anger subscale scores in the HA group, and this correlation was the only one that showed a significant group difference in the z-tests after Fisher's transformation. Individuals with the distracting communication style avoid conflicting emotion by blurring focus without paying attention to self, others, and situations [58]. The AQ-anger may reflect a tendency to harm others directly and physiological arousal and readiness for aggression [45]. Therefore, the result in the HA group suggests that the greater the direct aggression reflected by anger, the less choice of distracting communication style. This is consistent with the previous research that reported the higher the aggression or anger, the higher the possibility of direct violent action to resolve negative emotion [22].

In the task of practicing functional communication, the HA group did not show significant differences in the communication scores in the interactions with all dysfunctional communication styles compared with the LA group, nor did they show significant correlations between the communication scores and psychological scale scores. People with blaming communication are known to easily provoke anger in others [31]. Given that the HA group showed significantly higher NS-blaming than the LA group, the negative results in the task of practicing functional communication, which had no significant finding even in the CS-blaming, are not as expected. These are not because the virtual environment in the task did not induce conflict feelings in the HA group, but because there may be other confounding factors affecting the determination of the communication score based on self-evaluation. Decreased empathy and lack of objective understanding or judgment seen by people with high aggression may interfere with the objective self-evaluation of oneself [59]. Therefore, in order to obtain a more properly reflective response related to aggression and anger, it will be necessary to include indicators that provide objective information, not self-evaluation, such as bio-signals.

In the task of expressing empathy, the HA group showed no significant differences in the empathetic feeling score and emotional intensity score compared with the LA group. Although the empathetic feeling scores showed no significant correlation with any psychological scale scores in the HA group, the emotional intensity scores were positively correlated with the anger control-out scores. This result suggests the emotional intensity score, which reflects the degree to which highly aggressive individuals rate the emotion of the virtual person in the interpersonal context, may also appropriately reflect their aggression-related characteristics. The anger control-out score is a measure that reflects an individual's tendency to control their expression of anger [48]. The higher the score, the more energy is invested in controlling and regulating the expression of anger [60]. Meanwhile, inability or unwillingness to empathize is generally considered an intrinsic cause of a variety of aggressive behaviors, either physically [61] or sexually [62]. In our previous study, the emotional intensity scores were positively correlated with psychological rating scores that reflected perspective-taking, a cognitive dimension of an individual's empathy [35]. There was a report that the ability of taking perspective was related to measures of anger control [63]. The higher the degree of estimating the other's emotions, the greater the mediating effect on the effectiveness of aggression management [64]. Taken together, the emotional intensity score in our task of expressing empathy can be a good target for future intervention applications in highly aggressive individuals.

There should be only manageable adverse effects for acceptability when using the VR-based communication modification program. All participants in our study completed the program without dropouts. Given that the weighted mean SSQ score of the projection type of the head-mounted display used in the current study was 29.9 [65], the mean SSQ scores of participants (26.2 in the HA group and 22.0 in the LA group) suggests that the program may cause an acceptable level of adverse effects of cybersickness. 
Although the findings are encouraging, our study has several limitations. First, the program introduced a feedback method to enhance functional communication between people, but there are inevitable limitations in communication because it does not include the interactive function of recognizing and responding to speech at a level that allows for free conversation with participants. This will only be possible in an advanced version in the future with the help of artificial intelligence technology. Scheduling for repeated use and additional materials for training purposes rather than evaluation may also be required. Second, the composition of the two groups in this study was based on selfassessment of aggression, which may differ from the evaluation of a third party because it is a subjective evaluation. A more objective classification may be necessary for more accurate results, given a previous report that self-assessment was not well compatible with peer or teacher assessment in the investigation of the relationship between peer, teacher, and self-assessment of aggressive behavior in adolescents [66]. Third, the small sample size and only including young males limit the generalization of results. There is a need for more intensive applicability studies with a larger sample of different age and gender.

\section{Conclusions}

In summary, this study tried to show the potential of using the VR-based communication modification program consisting of the task of exploring the communication style, the task of practicing functional communication, and the task of expressing empathy in anger control training for people with high aggression in the future. The main results were that the NS-blaming was significantly greater in the HA group than in the LA group, the NS-distracting was negatively correlated with physical aggression and anger scores, and the emotional intensity scores were positively correlated with the anger control-out scores in the HA group. These results provide evidence that our program may properly reflect the individual's characteristics related to aggression and induce the proper response. Using our program can be an important starting point for developing more efficient methods for delivering VR programs to manage aggression in the general public.

Author Contributions: Conceptualization, Y.H.J. and J.-J.K.; methodology, J.-J.K.; software, J.-J.K.; validation, J.K. and Y.H.J.; formal analysis, J.K.; investigation, Y.-J.H., K.-D.B., and H.S.J.; resources, J.-J.K.; data curation, Y.-J.H.; writing — original draft preparation, J.K.; writing — review and editing, J.-J.K.; visualization, J.K.; supervision, J.-J.K.; project administration, Y.H.J.; funding acquisition, J.-J.K. All authors have read and agreed to the published version of the manuscript.

Funding: This work was supported by the Brain Research Program through the National Research Foundation of Korea (NRF) funded by the Ministry of Science, ICT and Future Planning (NRF2015M3C7A1065053).

Institutional Review Board Statement: The study was conducted in accordance with the Declaration of Helsinki and approved by the Institutional Review Board of Yonsei University Gangnam Severance Hospital (protocol code 3-2016-0107 and date of approval 2016-07-06).

Informed Consent Statement: Informed consent was obtained from all subjects involved in the study.

Data Availability Statement: Data is contained within the article.

Conflicts of Interest: The authors declare no conflict of interest.

\section{References}

1. Cohen, M.A. The monetary value of saving a high-risk youth. J. Quant. Criminol. 1998, 14, 5-33. [CrossRef]

2. Welsh, B.C.; Loeber, R.; Stevens, B.R.; Stouthamer-Loeber, M.; Cohen, M.A.; Farrington, D.P. Costs of juvenile crime in urban areas: A longitudinal perspective. Youth Violence Juv. Justice 2008, 6, 3-27. [CrossRef]

3. Britt, C.L. Health consequences of criminal victimization. Int. Rev. Vict. 2001, 8, 63-73. [CrossRef]

4. Kilpatrick, D.G.; Acierno, R. Mental health needs of crime victims: Epidemiology and outcomes. J. Trauma Stress 2003, 16, 119-132. [CrossRef]

5. Miller, T.R.; Fisher, D.A.; Cohen, M.A. Costs of Juvenile violence: Policy implications. Pediatrics 2001, 107, e3. [CrossRef]

6. Robinson, F.; Keithley, J. The impacts of crime on health and health services: A literature review. Health Risk Soc. 2000, 2, $253-266$. [CrossRef] 
7. Exner-Cortens, D.; Eckenrode, J.; Rothman, E. Longitudinal associations between teen dating violence victimization and adverse health outcomes. Pediatrics 2013, 131, 71-78. [CrossRef]

8. Taquette, S.R.; Monteiro, D.L.M. Causes and consequences of adolescent dating violence: A systematic review. J. Inj. Violence Res. 2019, 11, 137-147.

9. Greenberg, M.T.; Domitrovich, C.; Bumbarger, B. The prevention of mental disorders in school-aged children: Current state of the field. Prev. Treat. 2001, 4, 1a. [CrossRef]

10. Klein Tuente, S.; Bogaerts, S.; Bulten, E.; Keulen-de Vos, M.; Vos, M.; Bokern, H.; IJzendoorn, S.V.; Geraets, C.N.W.; Veling, W. Virtual reality aggression prevention therapy (VRAPT) versus waiting list control for forensic psychiatric inpatients: A multicenter randomized controlled trial. J. Clin. Med. 2020, 9, 2258. [CrossRef]

11. Weisz, J.R.; Kuppens, S.; Eckshtain, D.; Ugueto, A.M.; Hawley, K.M.; Jensen-Doss, A. Performance of evidence-based youth psychotherapies compared with usual clinical care: A multilevel meta-analysis. JAMA Psychiatry 2013, 70, 750-761. [CrossRef]

12. Sawyer, A.M.; Borduin, C.M.; Dopp, A.R. Long-term effects of prevention and treatment on youth antisocial behavior: A meta-analysis. Clin. Psychol. Rev. 2015, 42, 130-144. [CrossRef] [PubMed]

13. Foshee, V.A.; Bauman, K.E.; Ennett, S.T.; Suchindran, C.; Benefield, T.; Linder, G.F. Assessing the effects of the dating violence prevention program "Safe Dates" using random coefficient regression modeling. Prev. Sci. 2005, 6, 245-258. [CrossRef]

14. Sánchez-Jiménez, V.; Muñoz-Fernández, N.; Ortega-Rivera, J. Efficacy evaluation of "Date Adolescence": A dating violence prevention program in Spain. PLoS ONE 2018, 13, e0205802. [CrossRef]

15. Moore, M.; Kramer, D. Satir for beginners: Incongruent communication patterns in romantic fiction. ETC Rev. Gen. Semant. 1999, $56,429-437$.

16. Sun, W.; Li, D.; Zhang, W.; Bao, Z.; Wang, Y. Family material hardship and Chinese adolescents' problem behaviors: A moderated mediation analysis. PLOS ONE 2015, 10, e0128024. [CrossRef] [PubMed]

17. Wieck, M.M.; Blake, B.; Sellick, C.; Kenron, D.; DeVries, D.; Terry, S.; Krishnaswami, S. Utilizing technology to improve intraoperative family communication. Am. J. Surg. 2017, 213, 895-900. [CrossRef] [PubMed]

18. Williamson, H.C.; Altman, N.; Hsueh, J.; Bradbury, T.N. Effects of relationship education on couple communication and satisfaction: A randomized controlled trial with low-income couples. J. Consult. Clin. Psychol. 2016, 84, 156-166. [CrossRef] [PubMed]

19. Linder, J.A.; Levine, D.M. Health care communication technology and improved access, continuity, and relationships: The revolution will be uberized. JAMA Intern. Med. 2016, 176, 643-644. [CrossRef] [PubMed]

20. Schneider, C.; Arnot, M. Transactional school-home-school communication: Addressing the mismatches between migrant parents' and teachers' views of parental knowledge, engagement and the barriers to engagement. Teach. Teach. Educ. 2018, 75, 10-20. [CrossRef]

21. Law, G.C.; Neihart, M.; Dutt, A. The use of behavior modeling training in a mobile app parent training program to improve functional communication of young children with autism spectrum disorder. Autism 2017, 22, 424-439. [CrossRef] [PubMed]

22. Novaco, R.W.; Taylor, J.L. Reduction of assaultive behavior following anger treatment of forensic hospital patients with intellectual disabilities. Behav. Res. Ther. 2015, 65, 52-59. [CrossRef]

23. Satir, V.; Baldwin, M. Satir Step by Step: A Guide to Creating Change in Families; Science \& Behavior Books: Palo Alto, CA, USA, 1983.

24. Gehart, D.R.; Tuttle, A.R. Theory-Based Treatment Planning for Marriage and Family Therapists: Integrating Theory and Practice, 1st ed.; Brooks/Cole/Thomson: Pacific Grove, CA, USA, 2003.

25. Rasheed, J.M.; Rasheed, M.N.; Marley, J.A. Family Therapy: Models and Techniques; Sage Publications: Los Angeles, CA, USA, 2010.

26. Goldenberg, I.; Goldenberg, H. Family Therapy: An Overview, 6th ed.; Thomson, Brook/Cole: Pacific Grove, CA, USA, 2004.

27. Lau, W.K.W.; Leung, P.P.Y.; Chung, C.L.P. Effects of the Satir model on mental health: A randomized controlled trial. Res. Soc. Work Pract. 2018, 29, 775-785. [CrossRef]

28. Lum, W.; Smith, J.; Ferris, J. Youth suicide intervention using the Satir model. Contemp. Fam. Ther. 2002, 24, 139-159. [CrossRef]

29. Der Pan, P.J. The effectiveness of structured and semistructured Satir model groups on family relationships with college students in Taiwan. J. Spec. Group Work 2000, 25, 305-318. [CrossRef]

30. Yuk, H. The effect of Satir communication training program on conformity of university students' communication and self-esteem improvement. Korean J. Clin. Soc. Work 2015, 12, 1-23.

31. Carlson, M.W.; Oed, M.M.; Bermudez, J.M. Satir's communication stances and pursue-withdraw cycles: An enhanced emotionally focused therapy framework of couple interaction. J. Couple Relationsh. Ther. 2017, 16, 253-270. [CrossRef]

32. Baghcheghi, N.; Koohestani, H.R.; Rezaei, K. A comparison of the cooperative learning and traditional learning methods in theory classes on nursing students' communication skill with patients at clinical settings. Nurse Educ. Today 2011, 31, 877-882. [CrossRef]

33. Kesten, K.S. Role-play using SBAR technique to improve observed communication skills in senior nursing students. J. Nurs. Educ. 2011, 50, 79-87. [CrossRef]

34. Maabreh, S.M.; Faiez, F.; Al-Kousheh, M.; Maabarha, S. The effectiveness of a counseling program based on the model of Virginia Satir in improving quality of life and reducing negative communication patterns among a sample of wives in irbid governorate. Res. Humanit. Soc. Sci. 2020, 10, 84-96.

35. Kim, J.; Jung, Y.H.; Shin, Y.B.; Kim, M.K.; Eom, H.; Kim, E.; Kim, J.; Kim, J.J. Feasibility of a virtual reality-based interactive feedback program for modifying dysfunctional communication: A preliminary study. BMC Psychol. 2020, 8, 50. [CrossRef] [PubMed] 
36. Cieślik, B.; Mazurek, J.; Rutkowski, S.; Kiper, P.; Turolla, A.; Szczepańska-Gieracha, J. Virtual reality in psychiatric disorders: A systematic review of reviews. Complement. Ther. Med. 2020, 52, 102480. [CrossRef]

37. Ip, H.H.S.; Wong, S.W.L.; Chan, D.F.Y.; Byrne, J.; Li, C.; Yuan, V.S.N.; Lau, K.S.Y.; Wong, J.Y.W. Enhance emotional and social adaptation skills for children with autism spectrum disorder: A virtual reality enabled approach. Comput. Educ. 2018, 117, 1-15. [CrossRef]

38. Park, K.M.; Ku, J.; Choi, S.H.; Jang, H.J.; Park, J.Y.; Kim, S.I.; Kim, J.J. A virtual reality application in role-plays of social skills training for schizophrenia: A randomized, controlled trial. Psychiatry Res. 2011, 189, 166-172. [CrossRef] [PubMed]

39. Kim, H.E.; Hong, Y.J.; Kim, M.K.; Jung, Y.H.; Kyeong, S.; Kim, J.J. Effectiveness of self-training using the mobile-based virtual reality program in patients with social anxiety disorder. Comput. Hum. Behav. 2017, 73, 614-619. [CrossRef]

40. Hamilton, D.; McKechnie, J.; Edgerton, E.; Wilson, C. Immersive virtual reality as a pedagogical tool in education: A systematic literature review of quantitative learning outcomes and experimental design. J. Comput. Educ. 2021, 8, 1-32. [CrossRef]

41. Verhoef, R.E.J.; van Dijk, A.; Verhulp, E.E.; de Castro, B.O. Interactive virtual reality assessment of aggressive social information processing in boys with behaviour problems: A pilot study. Clin. Psychol. Psychother. 2021, 28, 489-499. [CrossRef]

42. Alsem, S.C.; van Dijk, A.; Verhulp, E.E.; De Castro, B.O. Using virtual reality to treat aggressive behavior problems in children: A feasibility study. Clin. Child Psychol. Psychiatry 2021, 26, 1062-1075. [CrossRef]

43. Clay, C.J.; Schmitz, B.A.; Balakrishnan, B.; Hopfenblatt, J.P.; Evans, A.; Kahng, S. Feasibility of virtual reality behavior skills training for preservice clinicians. J. Appl. Behav. Anal. 2021, 54, 547-565. [CrossRef]

44. Smeijers, D.; Bulten, E.H.; Verkes, R.J.; Koole, S.L. Testing the effects of a virtual reality game for aggressive impulse management: A preliminary randomized controlled trial among forensic psychiatric outpatients. Brain Sci. 2021, 11, 1484. [CrossRef]

45. Buss, A.H.; Perry, M. The aggression questionnaire. J. Pers. Soc. Psychol. 1992, 63, 452-459. [CrossRef] [PubMed]

46. Seo, S.G.; Kwon, S.M. Validation study for the Korean version of Aggression Questionnaire. Korean J. Clin. Psychol. 2002, 21, 487-501.

47. Lecrubier, Y.; Sheehan, D.V.; Weiller, E.; Amorim, P.; Bonora, I.; Harnett Sheehan, K.; Janavs, J.; Dunbar, G.C. The Mini International Neuropsychiatric Interview (MINI). A short diagnostic structured interview: Reliability and validity according to the CIDI. Eur. Psychiatry 1997, 12, 224-231. [CrossRef]

48. Spielberger, C.D. State-Trait Anger Expression Inventory-Professional Manual; Psychological Assessment Resources: Odessa, FL, USA, 1996.

49. Jeon, G.G.; Kim, D.J.; Lee, J.S. Development of the Korean version of State-Trait Anger Expression Inventory (STAXI). Korean J. Art Ther. 2000, 7, 33-50.

50. Barnes, H.L.; Olson, D.H. Parent-adolescent communication scale. In Family Inventories: Inventories Used in a National Survey of Families across the Family Life Cycle; Olson, D.H., Ed.; University of Minnesota: St. Paul, MN, USA, 1982.

51. Min, H.Y. Circumflex Model and Parent-Adolescent Communication. Master's Thesis, Yonsei University Graduate School, Seoul, Korea, 1990.

52. Kennedy, R.S.; Lane, N.E.; Berbaum, K.S.; Lilienthal, M.G. Simulator sickness questionnaire: An enhanced method for quantifying simulator sickness. Int. J. Aviat. Psychol. 1993, 3, 203-220. [CrossRef]

53. Ireland, J.L.; Adams, C. Implicit cognitive aggression among young male prisoners: Association with dispositional and current aggression. Int. J. Law Psychiatry 2015, 41, 89-94. [CrossRef] [PubMed]

54. Sjödin, A.K.; Wallinius, M.; Billstedt, E.; Hofvander, B.; Nilsson, T. Dating violence compared to other types of violence: Similar offenders but different victims. Eur. J. Psychol. Appl. Leg. Context 2017, 9, 83-91. [CrossRef]

55. Satir, V.; Banmen, J.; Gerber, J.G.M. The Satir Model: Family Therapy and Beyond; Science and Behavior Books: Palo Alto, CA, USA, 1991.

56. Chereji, S.V.; Pintea, S.; David, D. The relationship of anger and cognitive distortions with violence in violent offenders' population: A meta-analytic review. Eur. J. Psychol. Appl. Leg. Context 2012, 4, 59-77.

57. Lee, A.H.; DiGiuseppe, R. Anger and aggression treatments: A review of meta-analyses. Curr. Opin. Psychol. 2018, 19, 65-74. [CrossRef]

58. Brubacher, L. Integrating emotion-focused therapy with the Satir model. J. Marital Fam. Ther. 2006, 32, 141-153. [CrossRef]

59. Berkout, O.V.; Tinsley, D.; Flynn, M.K. A review of anger, hostility, and aggression from an ACT perspective. J. Contextual Behav. Sci. 2019, 11, 34-43. [CrossRef]

60. Fernandez, E.; Malvaso, C.; Day, A.; Guharajan, D. 21st century cognitive behavioural therapy for anger: A systematic review of research design, methodology and outcome. Behav. Cogn. Psychother. 2018, 46, 385-404. [CrossRef] [PubMed]

61. Lovett, B.J.; Sheffield, R.A. Affective empathy deficits in aggressive children and adolescents: A critical review. Clin. Psychol. Rev. 2007, 27, 1-13. [CrossRef] [PubMed]

62. Hanson, R.K.; Morton-Bourgon, K.E. The characteristics of persistent sexual offenders: A meta-analysis of recidivism studies. In Clinical Forensic Psychology and Law; Ronald Roesch, K.M., Ed.; Routledge: London, UK, 2007; pp. 67-76.

63. Day, A.; Mohr, P.; Howells, K.; Gerace, A.; Lim, L. The role of empathy in anger arousal in violent offenders and university students. Int. J. Offender Ther. Comp. Criminol. 2011, 56, 599-613. [CrossRef] [PubMed]

64. Zhou, Y.Q.; Gan, D.Z.Q.; Hoo, E.C.C.; Chong, D.; Chu, C.M. Evaluating the violence prevention program: Group and individual changes in aggression, anger, self-control, and empathy. J. Forensic Psychiatry Psychol. 2018, 29, 265-287. [CrossRef] 
65. Sharples, S.; Cobb, S.; Moody, A.; Wilson, J.R. Virtual reality induced symptoms and effects (VRISE): Comparison of head mounted display (HMD), desktop and projection display systems. Displays 2008, 29, 58-69. [CrossRef]

66. Pakaslahti, L.; Keltikangas-Jarvinen, L. Comparison of peer, teacher and self-assessments on adolescent direct and indirect aggression. Educ. Psychol. 2000, 20, 177-190. [CrossRef] 